\title{
Experimental infection of Wistar rats with 'Gastrospirillum suis'
}

\author{
E. N. MENDES, DULCIENE M. M. QUEIROZ, R. S. COIMBRA, SÍlVIA B. MOURA, A. J. A. \\ BARBOSA* and G. A. ROCHA
}

Laboratory of Research in Bacteriology and ${ }^{*}$ Department of Pathology, Faculdade de Medicina, Universidade Federal de Minas Gerais, Brazil

\begin{abstract}
In order to develop a model for the study of gastric spiral bacteria, and based on the observation that Wistar rats do not carry urease-positive spiral bacteria in their gastric mucosa, mucus from a pig naturally colonised by 'Gastrospirillum suis' (an organism with I6S rDNA $99.5 \%$ similar to that of ' $G$. hominis' type 1 ), was inoculated into 35 Wistar rats (test group). Fourteen rats were given mucus taken from ' $G$. suis'-negative swine (control group). Five test animals and two controls were killed 1, 2, 4, 8, 12, 26 and 52 weeks after inoculation. ' $G$-suis' was observed in the antral mucosa of all test rats but not in the gastric mucosa of any control animal. The number of organisms was high from the beginning of the infection and increased over the period of observation. The bacteria were seen deep in the gastric antral glands, especially in the advanced stages of infection. Histological study of two test rats killed 1 week after inoculation and of all rats killed from the second week after infection revealed the presence of a mild inflammatory response characterised by the infiltration of small numbers of mononuclear cells and scarce polymorphonuclear cells in the subglandular region of the antral mucosa. Lymphoid aggregates were observed in the antral mucosa of rats killed from 1 month onwards, and increased in size and number over the period of infection. Control animals did not have any histological changes in the gastric mucosa. The natural transmission of the bacterium from rat to rat was also investigated. Five noninoculated animals (contact group) and rats of the test group were maintained in the same cage and killed after 12 weeks. Two animals of the contact group showed slight infiltration of mononuclear cells in the antral mucosa, although they were not colonised by ' $G$. suis', a finding that supports the hypothesis of faecal-oral transmission of gastric Helicobacter spp. This animal model could be used not only to understand different aspects of the relationship between spiral bacteria and the gastric mucosa but also to obtain large numbers of the organism, free from other spiral bacteria to study some of its properties.
\end{abstract}

\section{Introduction}

'Gastrospirillum suis' is a tightly spiral organism that has been observed colonising the gastric mucosa of swine. 16S rRNA sequencing studies have shown that the bacterium belongs to the genus Helicobacter and is $99.5 \%$ similar to ' $G$. hominis' type 1 [1], one of the two species of ' $G$. hominis' described in the gastric mucosa of man [2]. This bacterium is probably involved in the pathogenesis of gastric disease in both man [3] and swine [4].

These spiral bacteria, except $H$. felis, have not been

Received 7 April 1995; revised version accepted 10 July 1995.

Corresponding author: M. M. Queiroz. cultured in vitro as yet but they can easily colonise the gastric mucosa of rodents, thus making it possible not only to maintain the organisms in vivo but also to develop animal models of infection [5-7]. There are now several animal models for the study of this group of micro-organisms including primates [8] gnotobiotic piglets $[9,10]$ and dogs [11] infected with $H$. pylori, gnotobiotic mice colonised by $H$. felis [12] or ' $G$. suis' [7] and germ-free rats given $H$. felis [13]. $H$. mustelae-infected ferrets [14] have also been proposed, but, for reasons related to the micro-organisms or the animal, or both, no completely satisfactory model is available as yet. When conventional mice are used the interpretation of the results may be hampered by the presence of $H$. muridarum, a normal inhabitant of the mouse intestine that can colonise the stomach [15-17]. Furthermore, animal models with human bacteria use only gnotobiotic animals. 
Thus, an ideal model for understanding infection by gastric spiral bacteria remains desirable. As ' $G$. suis' is now recognised as the same species as ' $G$. hominis' type 1 , and as conventional Wistar rats do not carry spiral bacteria in their stomachs [18], the ability of ' $G$. suis' to colonise the stomachs of conventional Wistar rats such that they might be used as an animal model to study ' $G$. suis' infection in particular and noncultivable spiral gastric bacteria in general was investigated.

\section{Materials and methods}

Mucus scraped from the gastric antrum of a Landrace pig naturally infected with ' $G$. suis', as confirmed by a positive urease test and carbol fuchsin-stained smears, was diluted 1 in 3 in saline, and $0.2 \mathrm{ml}$ samples of this suspension were inoculated into the stomachs of 35 2-4-month-old Wistar rats of both sexes lightly anaesthetised with ether (test group). Fourteen rats of the same strain and age were inoculated with mucus from the gastric antrum of a ' $G$. suis'-negative pig (control group). Test and control animals were kept in separate cages and had free access to water and to a commercial pelleted diet.

Five animals from the test group and two controls were killed by spinal dislocation 1, 2, 4, 8 and 12 weeks and 6 and 12 months after inoculation. The stomachs were opened longitudinally and thoroughly washed with saline $0.85 \%$. Fragments obtained from the antral and oxyntic mucosa were used for the urease test, carbol fuchsin-stained smears and culture. One specimen from each area was smeared on to a glass slide, heat fixed, stained with carbol fuchsin and examined by oil immersion microscopy for the presence of spiral bacteria [19]. The specimen for the urease test was inoculated into Christensen's urea $2 \%$ agar and examined within $24 \mathrm{~h}$ [20]. Specimens for culture were plated on to Belo Horizonte medium [21] and Skirrow's medium [22] and incubated in micro-aerophilic conditions at $37^{\circ} \mathrm{C}$ for up to 10 days. Specimens of the oxyntic mucosa and strips of the gastric wall taken along the lesser curvature of the stomach from the oesophagus to the duodenum were taken from each animal for histopathological examination. The fragments were fixed in Bouin's fluid for 18-24 h, dehydrated in an alcohol-xylene series and embedded in paraffin wax. Sections ( $4 \mu \mathrm{m}$ thick) were stained with haematoxylin and eosin for histological examination, and with carbol fuchsin for detection of spiral bacteria.

To study the natural transmission of ' $G$. suis', five uninoculated Wistar rats (contact group) and five test animals were maintained in the same cage. After 12 weeks, the animals were killed for histological and bacteriological investigation.
Animal passage of ' $G$. suis' was also investigated. Mucus obtained from the antrum of three of the five test animals killed 4 weeks after inoculation with ' $G$. suis' was diluted as described earlier and inoculated into the stomachs of three rats. After 4 weeks, the animals were killed and the gastric mucosa was examined for the presence of ' $G$. suis' by the urease test and carbol fuchsin-stained smears. Samples $(0.2 \mathrm{ml})$ of the suspensions prepared from the gastric mucus of these animals were inoculated into the stomachs of three other Wistar rats. This procedure was repeated six more times.

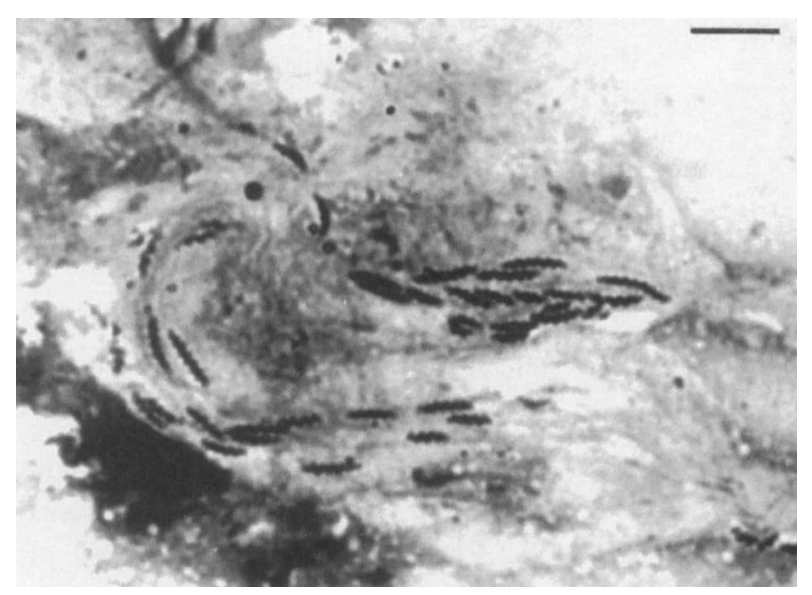

Fig. 1. Presence of ' $G$. suis' in a smear of the antral mucosa of an infected rat. (Carbol fuchsin staining, bar $=2.5 \mu \mathrm{m}$ ).

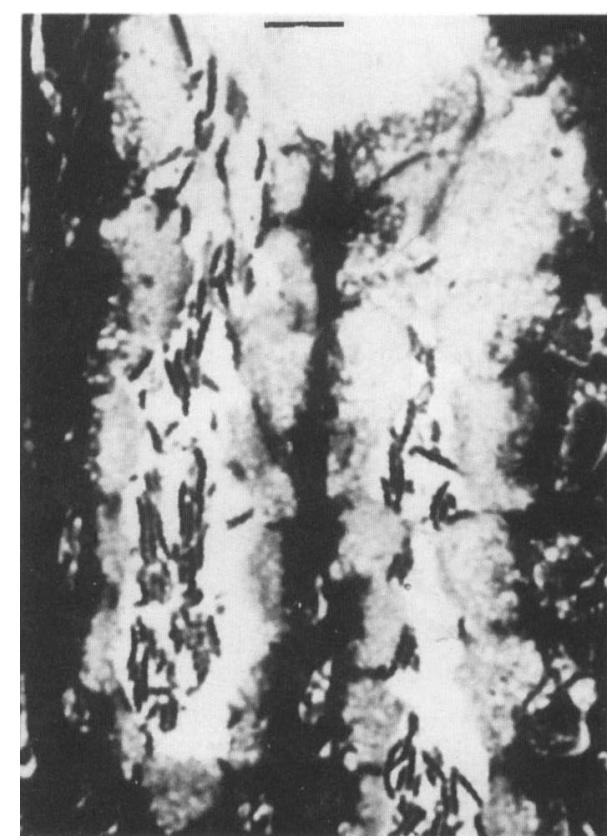

Fig. 2. Antral region of a Wistar rat 6 months after inoculation with ' $G$. suis' showing large numbers of the organism inside the pits. (Carbol fuchsin staining, bar $=2.5 \mu \mathrm{m}$ ) 


\section{Results}

The organism was shown to be present in the antral mucosa of all test rats by observation of smears (Fig. 1) and histological sections (Fig. 2). The infection was restricted to the stomach in all animals except one in which small numbers of bacteria were observed in the duodenum. The number of organisms observed in the gastric antrum was high (Fig. 2) from the outset and increased over the period of study. Also, the bacteria were seen deep in the gastric antral glands, especially late in the infection. The pre-formed urease test was also positive (within $3 \mathrm{~h}$ ) in all test animals. ' $G$. suis' was seen in the oxyntic mucosa of $15(42.9 \%)$ of 35 animals. One week after inoculation only one of five rats had ' $G$. suis' in the oxyntic mucosa. The number of animals showing the oxyntic mucosa colonised by the bacterium increased with time and 12 months after inoculation all 5 animals had ' $G$. suis' in that region of the stomach. In three of them, the urease test was positive, but only after incubation for $12 \mathrm{~h}$. ' $G$. suis' was not found in the antral or oxyntic mucosa of any control animal and was not isolated from any region of the control rats. Spiral bacteria morphologically resembling $H$. muridarum were not observed in smears or histological sections and were not isolated from the gastric mucosa of any animal.

Two of the five rats killed 1 week after inoculation and all test animals killed from the second week onwards showed a light inflammatory reaction in the subglandular portion of the antral mucosa. During the first 2 weeks, the inflammatory infiltrate consisted mostly of mononuclear cells. From the fourth to the fifty-second week, infiltration of scarce polymorphonuclear cells was present (Fig. 3). Small lymphoid aggregates were observed in test animals killed from the fourth week after inoculation onwards. The size and number of lymphoid aggregates increased with time, and lymphoid follicles with germinal centres

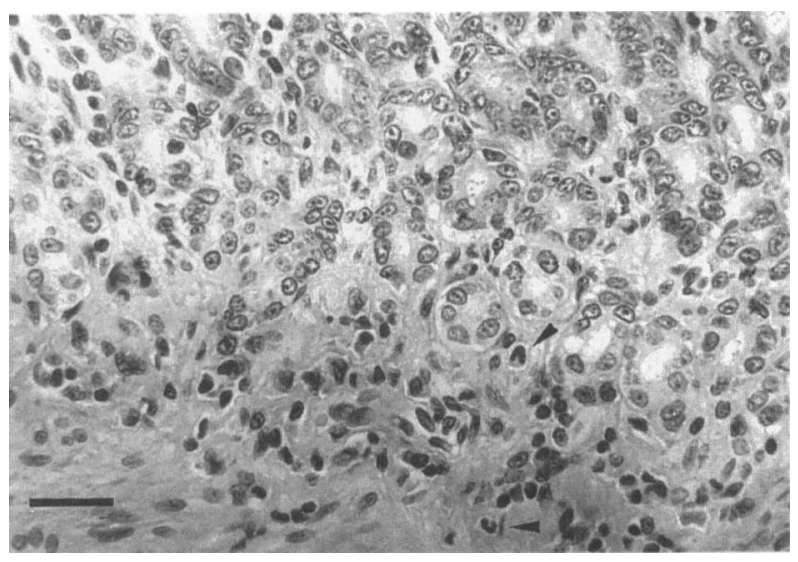

Fig. 3. Mild inflammatory infiltrate of the gastric antral region of a Wistar rat infected with ' $G$. suis' showing small numbers of mononuclear cells and scarce polymorphonuclear leucocytes (arrow heads). (H\&E, $\mathrm{bar}=16.0 \mu \mathrm{m})$.

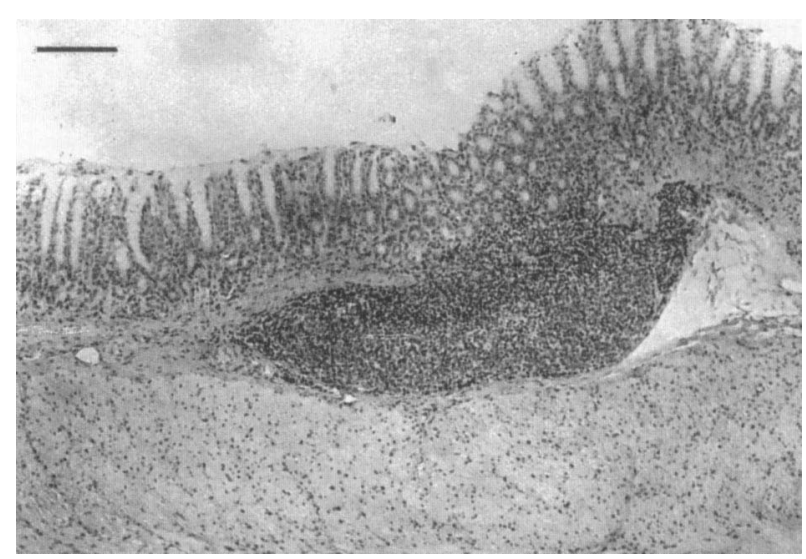

Fig. 4. Presence of a lymphoid follicle in the submucosa of the gastric antrum of a Wistar rat infected with ' $G$. suis' $(\mathrm{H} \& \mathrm{E}$, bar $=72.0 \mu \mathrm{m})$.

were observed in one of five test animals killed 6 months after inoculation and in two of five test rats killed after 1 year (Fig. 4). The antral mucosa of control animals and the oxyntic mucosa of both test and control animals were histologically normal. Atrophic changes were not observed in any animal.

Small numbers of mononuclear cells were observed in the lower third of the lamina propria of the antral mucosa in two of five contact animals, although ' $G$. suis' was not found in any of them.

When eight successive rat passages of ' $G$. suis' were performed, all animals inoculated with gastric mucus obtained from a rat infected with ' $G$. suis' became heavily colonised by the organism as confirmed by positive carbol fuchsin-stained smears and urease tests.

\section{Discussion}

The use of gnotobiotic or conventional rodents for maintaining non-cultivable gastric spiral bacteria has opened up new perspectives for the study of these micro-organisms. However, the maintenance of gnotobiotic animals is difficult and expensive and, when conventional mice are employed, the results cannot be properly interpreted as these animals may have stomachs naturally colonised by another spiral microorganism, H. muridarum [15-17].

Conventional Wistar rats, which do not have spiral bacteria in their gastric mucosa, were infected with 'G. suis' to determine whether this organism has the ability to induce an inflammatory response in the gastric mucosa of this animal.

Similarly to other gastric Helicobacter spp. $[12,14,23]$ the bacterium colonised only the gastric mucosa, emphasising the specific tropism of ' $G$. suis'. Large numbers of bacteria were observed early in the 
study in the gastric mucosa and increased with time, a fact that makes this model useful for obtaining large numbers of ' $G$. suis' free from other gastric spiral organisms.

The present study demonstrated that Wistar rats are susceptible to long-term, chronic, persistent infection by ' $G$. suis', and for this reason, this model could be employed to investigate late manifestations of infection by gastric spiral bacteria.

Colonisation of Wistar rats by ' $G$. suis' was associated with a mild inflammatory response characterised by the infiltration of small numbers of mononuclear cells and scarce polymorphonuclear cells which appeared from the fourth week after inoculation, a pattern similar to that reported by Fox et al. [13] in germ-free rats colonised by $H$. felis, but different from the inflammatory infiltrate observed in human patients infected with $H$. pylori [24] or ' $G$. hominis' [3]. Although the bacterium had been seen in both the antral and oxyntic gastric mucosa (most frequently in the antrum) a mild inflammatory reaction was observed only in the antral mucosa. $H$. pyloriinfection is also accompanied by an inflammatory response which is more frequent and intense in the antrum [24]. It is still unknown why the oxyntic mucosa seems to be more resistant to gastritis associated with gastric spiral bacteria.

There was also a definite increase in the number and size of lymphoid aggregates observed in the antral submucosa with time. Similar results have been reported in $H$. pylori-infected human subjects. According to some authors $[25,26]$, this lymphoid proliferation may result from the chronic antigenic stimulation caused by the micro-organism. Based on recent findings, it has been suggested that $H$. pylori triggers the development not only of gastric carcinoma [27] but also of mucosa-associated lymphoid tissue (MALT) in the stomach, a necessary substrate on which lymphoma could develop [28, 29]. However, this hypothesis needs to be tested in an animal model. No atrophic lesion was observed in ' $G$. suis'-infected animals but the increasing lymphoid proliferation observed was clearly associated with the organism as it was not found in the controls. Similarly to the distribution of MALT lymphomas in man [29], lymphoid aggregates and follicles were most frequently found in the antral mucosa of infected rats.

Uninoculated rats maintained in contact with animals inoculated with ' $G$. suis' developed an inflammatory response in the antral mucosa, albeit the bacterium was not found in their stomachs, a finding that supports the hypothesis that gastric helicobacters are disseminated by the faecal-oral route. Fox et al. [13], in a study of $H$. felis transmission among rats, observed a transient humoral response in uninoculated rats maintained with inoculated animals. In accordance with our findings, the animals were not colonised by the bacterium. According to the authors, the immune response observed was probably due to stimulation by cell products of $H$. felis that might have been present in the faeces of infected animals. These antigens may be ingested by non-infected animals as rats are coprophagous. This may also be a plausible explanation for the current findings.

We were able to maintain ' $G$. suis' obtained from the stomach of swine by successive passages in Wistar rats for up to 32 weeks, when the experiments were stopped. The micro-organism tolerated eight passages from rat to rat, as shown by the colonisation of all animals given the bacterium. This method can be used to maintain the organism in the laboratory.

In conclusion, conventional Wistar rats are highly susceptible to experimental infection with ' $G$. suis', which induces a slight inflammatory response in the mucosa of the gastric antrum. As these animals are easily and inexpensively maintained in the laboratory, and as they are not naturally colonised by gastric spiral micro-organisms [18], they may represent a good model for the study of gastric spiral bacteria and also for enriching and maintaining these microorganisms in the laboratory. For instance, as ' $G$. suis' and ' $G$. hominis' type 1 are now considered to be the same species [1], this model could be used for developing a better understanding of the relationship between this bacterium and both human and swine gastric mucosa, and also for obtaining large numbers of bacteria that could be useful for the study of their morphology, physiology and genetics.

This work was supported by grants from CNPq and PRPq IUFMG Brazil.

\section{References}

1. Mendes EN, Queiroz DMM, Dewhirst FE, Paster BJ, Rocha GA, Fox JG. Are pigs a reservoir host for human Helicobacter infection? (Abstract). Am J Gastroenterol 1994; 89: 1296.

2. Solnick JV, O'Rourke J, Lee A, Paster BJ, Dewhirst FE Tompkins LS. An uncultured gastric spiral organism is a newly identified Helicobacter in humans. J Infect Dis 1993; 168: 379-385.

3. Heilmann KL, Borchard F. Gastritis due to spiral shaped bacteria other than Helicobacter pylori: clinical, histological, and ultrastructural findings. Gut 1991; 32: 137-140.

4. Queiroz DMM, Rocha GA, Mendes EN, Moura SB, Oliveira CA. Swine experimentally infected with Helicobacter as an animal model of ulcerogenesis. (Abstract). Am J Gastroenterol 1994; 89: 1320 .

5. Dick E, Lee A, Watson G, O'Rourke J. Use of the mouse for the isolation and investigation of stomach-associated, spiralhelical shaped bacteria from man and other animals. $J$ Med Microbiol 1989; 29: 55-62.

6. Mendes EN, Queiroz DMM, Rocha GA et al. "In vivo" culture improves the diagnosis of 'Gastrospirillum suis' infection. (Abstract). Irish J Med Sci 1992; 161 Suppl 10: 78

7. Moura SB, Queiroz DMM, Mendes EN, Nogueira AMMF, Rocha GA. The inflammatory response of the gastric mucosa of mice experimentally infected with "Gastrospirillum suis". $J$ Med Microbiol 1993; 39: 64-68. 
8. Baskerville A, Newell DG. Naturally occurring chronic gastritis and $C$. pylori infection in the Rhesus monkey: a potential model for gastritis in man. Gut 1988; 29: 465-472.

9. Krakowka S, Morgan DR, Kraft WG, Leunk RD. Establishment of gastric Campylobacter pylori infection in the neonatal gnotobiotic piglet. Infect Immun 1987; 55: 2789-2796.

10. Lambert JR, Borromeo M, Pinkard KJ, Turner H, Chapman CB, Smith ML. Colonization of gnotobiotic piglets with Campylobacter pyloridis - an animal model? J Infect Dis 1987; 155: 1344.

11. Radin MJ, Eaton KA, Krakowka $\mathrm{S}$ et al. Helicobacter pylori gastric infection in gnotobiotic beagle dogs. Infect Immun 1990; 58: 2606-2612.

12. Lee A, Fox JG, Otto G, Murphy J. A small animal model of human Helicobacter pylori active chronic gastritis. Gastroenterology 1990; 99: 1315-1323.

13. Fox JG, Lee A, Otto G, Taylor NS, Murphy JC. Helicobacter felis gastritis in gnotobiotic rats: an animal model of Helicobacter pylori gastritis. Infect Immun 1991; 59: 785-791.

14. Fox JG, Correa P, Taylor NS et al. Helicobacter mustelaeassociated gastritis in ferrets: an animal model of Helicobacter pylori gastritis in humans. Gastroenterology 1990; 99: 352-361.

15. Lee A. Spiral organisms: what are they? A microbiologic introduction to Helicobacter pylori. Scand J Gastroenterol 1991; 26: Suppl 187: 9-22.

16. Queiroz DMM, Contigli C, Coimbra RS et al. Spiral bacterium associated with gastric, ileal and caecal mucosa of mice. Lab Animals 1992; 26: 288-294.

17. Moura SB, Queiroz DMM, Mendes EN, Rocha GA. Natural colonisation of mice gastroinestinal tract by Helicobacter muridarum. Microecol Ther (in press).

18. Coimbra RS, Queiroz DMM, Martin PWL et al. Natural infection of the gastric and intestinal mucosa of rats with Helicobacter muridarum. Microecol Ther (in press).

19. Resende LMH, Queiroz DMM, Mendes EN et al. Comparison of the urease test and of direct smear examination in the control of treatment of Helicobacter pylori-induced infection. Braz J Med Biol Res 1993; 26: 699-702.

20. Queiroz DMM, Rocha GA, Mendes EN, Lage AP, Carvalho ACT, Barbosa AJA. Spiral microorganism in the stomach of pigs. Vet Microbiol 1990; 24: 199-204.

21. Queiroz DMM, Mendes EN, Rocha GA. Indicator medium for isolation of Campylobacter pylori. J Clin Microbiol 1987; 25: 2378-2379.

22. Phillips MW, Lee A. Isolation and characterization of a spiral bacterium from the crypts of rodent gastrointestinal tracts. Appl Environ Microbiol 1983; 45: 675-683.

23. Mendes EN, Queiroz DMM, Rocha GA et al. Histopathological study of porcine gastric mucosa with and without a spiral bacterium ("Gastrospirillum suis"). J Med Microbiol 1991; 35: 345-348.

24. Queiroz DMM, Barbosa AJA, Mendes EN et al. Distribution of Campylobacter pylori and gastritis in the stomach of patients with and without duodenal ulcer. Am $J$ Gastroenterol 1988; 83: 1368-1370.

25. Wyatt JI, Rathbone BJ. Immune response of the gastric mucosa to Campylobacter pylori. Scand J Gastroenterol 1988; 23 Suppl 142: $44-49$.

26. Stolte M, Eidt $S$. Lymphoid follicles of the antral mucosa: immune response to Campylobacter pylori? J Clin Pathol 1989; 42: 1269-1271.

27. Parsonnet J, Vandersteen D, Goates J, Sibley RK, Pritikin J, Chang Y. Helicobacter pylori in intestinal- and diffuse-type gastric adenocarcinomas. J Natl Cancer Inst 1991; 83: 640-643.

28. Wotherspcon AC, Ortiz-Hidalgo C, Falzon MR, Isaacson PG. Helicobacter pylori-associated gastritis and primary B-cell gastric lymphoma. Lancet 1991; 338: 1175-1176.

29. Genta RM, Hammer HW, Graham DY. Gastric lymphoid follicles in Helicobacter pylori infection: frequency, distribution, and response to triple therapy. Hum Pathol 1993; 24: $577-583$. 